\title{
The accuracy of fine-needle aspiration cytology for diagnosis of parotid gland masses: clinicopathological study of 114 patients
}

\author{
Jens Kristjan GUDMUNDSSON², Aida AJAN', Jahan ABTAHI' \\ 1- Linköping University Hospital, Department of Oral and Maxillofacial Surgery, Linköping, Sweden.
}

2- Eskilstuna Hospital, Department of Otorhinolaryngology, Eskilstuna, Sweden.

Corresponding address: Jahan Abtahi - Department of Oral and Maxillofacial Surgery - Linköping University Hospital - Linköping - Sweden - phone: +46 (0)70 7566997 - e-mail: jahan.linkoping@gmail.com - e-mail: jahan.abtahi@regionostergotland.se

Submitted: April 20, 2016 - Modification: July 20, 2016 - Accepted: July 27, 2016

\section{ABSTRACT}

\begin{abstract}
bjective: Fine-needle aspiration cytology is a valuable method for preoperative assessment of head and neck tumors. However, its accuracy in detection of salivary gland masses is controversial compared with other methods. The aim of this work was to evaluate the effectiveness and accuracy of fine-needle aspiration cytology (FNAC) in the diagnosis of parotid gland masses. Material and Methods: Over a 10-year period, 126 parotid gland masses were resected. Retrospective chart reviews of 114 patients were performed. The results of FNAC and final histological diagnosis were compared and the accuracy of FNAC was determined. Results: Final histological evaluation revealed 11 malignant tumors and 103 benign lesions. Pleomorphic adenoma was the most common neoplasm (63\%), followed by Warthin's tumor (17.5\%). The sensitivity of FNAC in detecting malignant tumors was $73 \%$ and the specificity was $97 \%$. Positive predictive value (PPV) was $73 \%$ and negative predictive value (NPV) was $97 \%$. The overall accuracy of FNAC in detecting parotid masses was 95\%. False-negative diagnosis was found in mucoepidermoid carcinoma, acinic cell carcinoma, and epithelial-myoepithelial carcinoma whereas there was false-positive diagnosis in cases of pleomorphic adenoma and normal parotid gland tissue. Conclusion: FNAC is a reliable minimally invasive diagnostic method with a high sensitivity in diagnosis of lesions in parotid glands. The sensitivity of detection of malignant tumors in parotid glands was low due to the biopsy technique used, and depended on tumor location. Postoperative complications decreased after superficial parotidectomy.
\end{abstract}

Keywords: Fine-needle. Citology. Parotid disease. Diagnosis. Biopsy.

\section{INTRODUCTION}

Salivary gland tumors are a morphologically and clinically diverse group of neoplasms, which may present significant diagnostic and management challenges. In the western world, the estimated overall incidence is approximately 2.5-3.0 cases per 100,000 per year ${ }^{21}$. Malignant salivary gland neoplasms account for more than $0.5 \%$ of all malignancies and approximately $3-5 \%$ of all head and neck cancers ${ }^{21}$. In Sweden, the incidence of parotid gland tumors is 0.77 cases per 100,000 women and 1.16 cases per 100,000 men. In comparison, the overall incidence of salivary gland tumors during the same year was 0.99 in women and 1.49 in men ${ }^{7}$. Several imaging modalities have been used for diagnosis of parotid masses, including magnetic resonance imaging (MRI) and computed tomography $(C T)^{16,28}$. MRI provides anatomical information about parotid tumor location and can be a useful tool to determine whether the mass is benign or malignant ${ }^{16}$. Fine-needle aspiration cytology (FNAC) is a globally accepted method in the preoperative evaluation of head and neck tumors. This method provides excellent distinction between benign and malignant parotid tumors, and has other advantages: it is inexpensive, easy to perform, relatively painless, and well tolerated ${ }^{1}$. The procedure is a cytodiagnostic method whereby a needle is used to acquire a sample of cells and 
microparticles of tissue for morphological analysis. Compared with histological results, a concordance of $86 \%$ has been observed, with a specificity of $98 \%$, a sensitivity of $84 \%$, and a diagnostic accuracy of $94 \%{ }^{1}$. However, the value of FNAC for the diagnosis of parotid gland masses. has been questioned due to its low sensitivity regarding malignancy, variation in reported results, and the belief that most parotid masses require surgery in any case $\mathrm{c}^{17,20}$. Tumors of the parotid gland can be removed by superficial parotidectomy and total parotidectomy ${ }^{10}$. Enucleation of parotid gland masses is not the first choice of treatment, and may increase the risk of recurrence ${ }^{29}$. Several complications have been associated with parotid gland surgery, such as facial nerve disturbance, Frey's syndrome, and great auricular nerve paresthesia ${ }^{9,27}$. Factors that affect facial nerve dysfunction include malignant tumors, lesion sizes, operating time, and type of parotidectomy (total vs. superficial) ${ }^{2,3,9,27}$. The aim of this study was to evaluate the diagnostic value of FNAC in detection of parotid gland tumors at our clinic (especially for detection of malign lesions). The efficacy of FNAC was determined by comparing cytological results with final histological results in a retrospective study. In addition, clinical outcome of surgery and postoperative parameters were also evaluated.

\section{MATERIAL AND METHODS}

\section{Identification of study population}

Eskilstuna Hospital provides healthcare to more than a quarter of a million inhabitants. Over a 10year period (January 2003 to December 2014), masses in the salivary gland tumors of 126 patients were resected. Patients treated between J anuary and December 2006 were excluded due to an error in the patients' electronic medical records. The medical records of 12 patients could not be located, so 114 patients ( 61 males and 53 females) with a mean age of 56.4 years (range 18-85 years) were included in this study for further investigation. Three surgeons performed the surgical procedures. Intraoperative facial nerve monitoring with a nerve stimulator was used in all cases. We used our department's electronic database and clinical files to identify all patients who were diagnosed with a mass in the parotid gland. The ICD-10 codes D11.0, D11.9, C08.8, C08.9, and C07.9 were used to identify subjects from the database; this was followed by review of the medical records to confirm the diagnosis.

Information regarding patient demographics, FNAC results, and final histological diagnosis results was evaluated. The postoperative outcome, including postoperative infection and hematoma, facial nerve disturbance, and Frey's syndrome was also registered. The preoperative FNAC results were compared with the final histological diagnosis from the surgical specimens. Data on age, gender, tumor type, and postoperative complications (facial nerve disturbance, postoperative infection, Frey's syndrome, and hematoma) were collected from the clinical records. Facial nerve disturbance was classified into four categories: (1) none, (2) transient (0-2 months), (3) less transient (2-12 months), and (4) permanent. Patients with radiologically verified and FNAC-verified cysts in parotid glands were excluded. Patients with inconclusive FNAC results were also excluded.

\section{Fine-needle aspiration cytology technique}

FNAC was performed using a 22-gauge needle attached to a 10-mL plastic syringe mounted on a syringe holder for a single hand grip. The aspirated material was deposited onto five clean glass slides without using local anesthesia. The number of aspirations varied between 2 and 3, depending on the accessibility of the tumor. FNAC air-dried smears were stained with Giemsa stain and the slides were then examined under a light microscope (Olympus Cx31, Nishi Shinjuku 2-chome, Tokyo, Japan), and results were reported according to the World Health Organization guidelines regarding parotid gland neoplasm.

All FNAC samples and tumor specimens were analyzed by the same laboratory (Unilabs Laboratoriemedicin at Mälarsjukhuset, diagnostikcentrum Eskilstuna, Sweden). Patients with FNAC-verified malignant tumors were referred to the head and neck cancer center at Örebro University Hospital for further cancer treatment.

The cytology laboratory provided three types of histological results: (1) benign aspiration cytology, (2) suspicious or malignant aspiration cytology, and (3) non-contributory aspiration cytology (indeterminate or inconclusive).

\section{Statistics}

FNAC-based diagnoses were compared with diagnoses from histological examination of specimens. We calculated the sensitivity regarding the presence of malignancy (true positive/true positive + false negative), specificity regarding absence of malignancy (true negative/true negative + false positive), positive predictive value (PPV) (true positive/true positive + false positive), negative predictive value (NPV) (true negative/ true negative + false negative), and accuracy of FNAC (true positive + true negative/total). Confidence intervals were computed at the $95 \%$ level. The FNAC and final histological diagnosis results are presented in terms of frequencies and percentages. Kappa value was also used to compare 
the agreement between the FNAC-based diagnosis and the biopsy-based diagnosis. Statistical analysis was carried out using SPSS (version 12.0).

\section{RESULTS}

\section{Demographic and histological outcome}

One hundred fourteen patients with parotid masses ( 61 males and 53 females) with a mean age of 56.4 years (range 18-85 years) were included in the study. Mean duration of follow-up was 66 months (range 3-132 months). The female-to-male ratio was approximately 1 to 1.1 . Tumors were mainly located in the superficial parotid lobe ( 87 cases, $76 \%$ ), but 27 tumors ( $24 \%$ ) were in the deep parotid lobe. FNAC of the deep portion of parotid mass was conducted in 7 cases $(6 \%)$, whereas in 20 cases $(17.5 \%)$ this procedure was performed using ultrasound-guided biopsy.

Parotid tumors were resected via superficial parotidectomy $(n=91 ; 79.8 \%)$. Total parotidectomy was performed in 18 cases with deep-lobe tumors $(15.8 \%)$, and enucleation or superficial partial parotidectomy was performed in 2 cases $(1.7 \%)$. Final histological evaluation revealed 11 malignant tumors (9.6\%) and 103 benign lesions (90.3\%). Pleomorphic adenoma was the most common neoplasm (72 cases; 63\%), followed by Warthin's tumor (20 cases; $17.5 \%$ ).

\section{Accuracy of fine-needle aspiration cytology}

FNAC was performed in 94 patients ( 4 tumors in deep portions and 90 tumors in superficial parotid glands). In 20 cases ( $21 \%$ ) with tumors located in deep parts of parotid glands, FNAC was complemented with ultrasound. In 108 of 114 cases $(94.7 \%)$, preoperative FNAC and final histopathological findings were conclusive. The overall accuracy of FNAC for parotid masses was estimated to be $95 \%$. False-negative diagnoses were found in mucoepidermoid carcinoma $(n=1$; $1.4 \%)$, acinic cell carcinoma $(n=1 ; 1.4 \%)$, and

Table 1- The accuracy of fine-needle aspiration cytology (FNAC). Comparison of FNAC and final histological diagnosis (FHD)

\begin{tabular}{|c|c|c|c|c|c|c|c|}
\hline \multirow{2}{*}{$\begin{array}{c}\text { Accuracy of FNAC } \\
\text { vs. FHD } \\
\text { FHD } \\
\text { Benign } \\
\end{array}$} & \multirow{2}{*}{$\begin{array}{l}\text { Location } \\
\text { S/D } \\
\text { No. }\end{array}$} & \multirow{2}{*}{$\begin{array}{c}\text { Method } \\
\text { FNAC/UGB } \\
\text { No. }\end{array}$} & \multicolumn{2}{|c|}{$\begin{array}{l}\text { Diagnosed as cancer } \\
\text { (false positive) }\end{array}$} & \multicolumn{2}{|c|}{$\begin{array}{l}\text { Correctly diagnosed } \\
\text { (as benign) }\end{array}$} & \multirow{2}{*}{$\begin{array}{l}\text { Total } \\
\text { No. }\end{array}$} \\
\hline & & & No. & $\%$ & No. & $\%$ & \\
\hline Pleomorphic adenoma & 6,4 & 8,25 & 2 & 2.7 & 72 & 97.3 & 74 \\
\hline Warthin's tumor & $19 / 1$ & $19 / 1$ & 0 & 0 & 20 & 100 & 100 \\
\hline Normal parotid tissue & 2 & $3 / 0$ & 1 & 1.4 & 2 & 66.6 & 20 \\
\hline Basal cell adenoma & 2 & 2 & 0 & 0 & 3 & 100 & 3 \\
\hline Sialoadenitis & $1 / 0$ & $1 / 0$ & 0 & 0 & 1 & 100 & 1 \\
\hline Benign oncocytoma & $0 / 1$ & $0 / 1$ & 0 & 0 & 1 & 100 & 1 \\
\hline Lymphatic tissue & $1 / 0$ & $1 / 0$ & 0 & 0 & 1 & 100 & 1 \\
\hline \multirow[t]{2}{*}{ Total } & $89 / 14$ & $92 / 11$ & 3 & & 100 & & 103 \\
\hline & $\begin{array}{l}\text { Location } \\
\text { S/D }\end{array}$ & $\begin{array}{c}\text { Method } \\
\text { FNAC/UGB }\end{array}$ & \multicolumn{2}{|c|}{$\begin{array}{l}\text { Diagnosed as benign } \\
\text { (false negative) }\end{array}$} & \multicolumn{2}{|c|}{$\begin{array}{l}\text { Correctly diagnosed } \\
\text { (as malignant) }\end{array}$} & Total \\
\hline $\begin{array}{c}\text { FHD } \\
\text { Malignant } \\
\end{array}$ & No. & No. & No. & $\%$ & No. & $\%$ & No. \\
\hline Malignified & $0 / 2$ & $0 / 2$ & 0 & 0 & 2 & 100 & 2 \\
\hline \multicolumn{8}{|l|}{ pleomorphic adenoma } \\
\hline Acinic cell carcinoma & $0 / 1$ & $1 / 0$ & 1 & 1.4 & 0 & 0 & 1 \\
\hline Mucoepidermoid carcinoma & 0,5 & 2 & 1 & 1.4 & 2 & 66.6 & 3 \\
\hline Lymphoma & $1 / 0$ & $1 / 0$ & 0 & 0 & 1 & 100 & 1 \\
\hline Epithelial-myoepithelial & $0 / 1$ & $1 / 0$ & 1 & 1.4 & 0 & 0 & 1 \\
\hline \multicolumn{8}{|l|}{ Carcinoma } \\
\hline Adenocarcinoma & $0 / 3$ & $0 / 3$ & 0 & 0 & 3 & 100 & 3 \\
\hline Total & & & 3 & & 8 & & 11 \\
\hline All cases & $2 / 9$ & $5 / 6$ & 6 & & 108 & & 114 \\
\hline
\end{tabular}

FNAC, fine-needle aspiration cytology; FHD, final histological diagnosis; UGB, ultrasound-guided biopsy. 
epithelial-myoepithelial carcinoma $(n=1 ; 1.4 \%)$ whereas there were false-positive diagnoses in cases of pleomorphic adenoma $(n=2 ; 2.7 \%)$ and in normal parotid tissue $(n=1 ; 1.4 \%)$ (Table 1$)$.

FNAC results did not correlate with histology in 6 specimens $(6.4 \%), 3$ of which were benign $(3 \%)$ and 3 malignant ( $3 \%$ ). Final histological evaluation showed 11 malignant tumors ( 8 tumors were diagnosed correctly by FNAC and 3 were classified as benign). Thus, FNAC failed to give a correct cytological result in 3 cases ( $27.3 \%)$. The summary estimates that the sensitivity and specificity were $73 \%(95 \% \mathrm{Cl} 39-94)$ and $97 \%(95 \% \mathrm{Cl}$ 92-99), respectively. The PPV was $73 \%$ and the NPV was 97\% (Table 2). The kappa statistic for the degree of agreement between FNAC and histological results was 0.94 .

In summary, the study showed low sensitivity for malignant tumors. However, regarding the location of tumors, these three false-negative cases were located in the deep portion of the parotid gland and they were diagnosed by FNAC without ultrasoundguided biopsy.

\section{Surgical outcome and postoperative complications}

Tumors were mainly located in the superficial lobe ( 87 cases, $76 \%)$, but $27(24 \%)$ were in the deep lobe of the parotid gland. The most common complication of parotid gland surgery was transient facial nerve palsy. Of 114 patients, 39 (34\%) had a mild transient palsy, $9(7.9 \%)$ had a transient palsy lasting more than 2 months, and only one patient $(0.9 \%)$ had permanent facial nerve palsy at 1-year follow-up. Of 39 patients with short-term facial nerve weakness (lasting 0-2 months), 21 $(53.8 \%)$ had tumors located in the deep parotid lobe. Postoperative infection was found in 7 cases $(5.8 \%)$. Nine patients $(7.5 \%)$ had a recurrence of the tumor, 1 patient $(0.8 \%)$ had hemorrhage, and 3 patients $(2.5 \%)$ developed Frey's syndrome.

\section{DISCUSSION}

FNAC is a simple, inexpensive, and atraumatic method for preoperative assessment of tumors, lymph nodes, and other lesions in the head and neck. It is a safe procedure requiring minimal equipment, with a very low risk of cancer cell implantation ${ }^{11,25}$. Fine-needle aspiration of parotid glands may lead to hemorrhage, facial nerve injury, and fibrosis ${ }^{5}$. Infarction or metaplastic transformation of benign tumor has also been mentioned in the literature ${ }^{8}$. In this study, there were a few cases of infection $(5.8 \%)$, hemorrhage $(0.8 \%)$, and Frey's syndrome $(2.5 \%)$ as a result of FNAC of the parotid mass lesions. No long-term facial nerve dysfunction was observed 1 year after surgery.

Several imaging modalities have been used for diagnostics of parotid masses, including CTscan, MRI, and ultrasound-guided core needle biopsy (USCB) ${ }^{15,16,28}$. CT-scan and MRI provide information about size and location of the tumor. However, comparing these two methods, CT-scan accurately assesses parotid lesions while MRI shows the relationship to adjacent structures better ${ }^{16,28}$. In a clinical study by Inohara, et al. ${ }^{16}$ (1993), the relative value of FNAC and MRI in relation to the differential diagnosis of benign and malignant parotid mass lesions was investigated. Eighty-one

Table 2- The reliability of fine-needle aspiration cytology (FNAC) and correlation with final histological diagnosis (FHD)

\begin{tabular}{|c|c|c|c|c|}
\hline \multicolumn{5}{|c|}{ Reliability of FNAC } \\
\hline \multirow[t]{2}{*}{ Kappa } & \multirow[t]{2}{*}{ Value (\%) } & \multicolumn{3}{|c|}{$95 \%$ confidence interval } \\
\hline & & Lower limit & Upper limit & \\
\hline Sensitivity & $73 \%$ & $39 \%$ & $94 \%$ & 0.947 \\
\hline Specificity & $97 \%$ & $92 \%$ & $99 \%$ & \\
\hline Positive predictive value & $73 \%$ & $39 \%$ & $94 \%$ & \\
\hline Negative predictive value & $97 \%$ & $92 \%$ & $99 \%$ & \\
\hline \multicolumn{5}{|c|}{ Correlation between FNAC and FHD } \\
\hline \multicolumn{5}{|c|}{ Final histological diagnosis, FHD } \\
\hline \multicolumn{2}{|c|}{ Cytological diagnosis, FNAC } & Malignant & Benign & Total \\
\hline Malignant & \multicolumn{2}{|c|}{$8(\mathrm{TP})$} & $3(\mathrm{FP})$ & 11 \\
\hline Benign & \multicolumn{2}{|c|}{$3(\mathrm{FN})$} & $100(\mathrm{TN})$ & 103 \\
\hline Total & \multicolumn{2}{|c|}{11} & 103 & 114 \\
\hline
\end{tabular}

FNAC, fine-needle aspiration cytology; FHD, final histological diagnosis; TP, true positive; TN, true negative; FP, false positive; FN, false negative. 
patients with parotid mass lesions ( 60 benign and 21 malignant) who had undergone FNAC and MRI preoperatively were retrospectively reviewed. The sensitivity, specificity, and accuracy of FNAC and MRI were 90\%/95\%/94\% and $81 \% / 92 \% / 89 \%$, respectively, and the combination of FNAC and MRI conferred no diagnostic advantage over either modality alone ${ }^{14}$. Haldar, et al. ${ }^{13}$ (2015) reported the largest series of patients with parotid neoplasm who underwent USCB. One hundred twenty specimens were analyzed with FNAC, 313 were analyzed with USCB, and 259 surgical specimens were analyzed from 397 patients. The sensitivity and specificity of FNAC were $70 \%$ and $89 \%$, respectively, and the corresponding figures for USCB were $93 \%$ and $100 \%$. Similar findings have been reported by others ${ }^{15}$.

The importance of FNAC in distinguishing malignant parotid mass lesions from benign ones has been investigated by several authors ${ }^{1,19}$. Despite the simplicity of the method, the accuracy of FNAC varies depending on the precision and experience of pathologists ${ }^{2}$. Diagnostic difficulties with FNAC are most common in lesions involving pleomorphic adenoma, basal cell adenoma, lowgrade mucoepidermoid carcinoma, and acinic cell carcinoma ${ }^{3}$. Moreover, the diagnosis is more difficult in low-grade mucoepidermoid carcinomas where thick mucinous liquid is seen in the background with a paucicellular smear ${ }^{3}$. In such cases, malignant tumors are mistakenly reported as benign lesions ${ }^{3}$. This occurred with one of our patients with a tumor in the deep portion of the parotid gland (Figure 1 ). The malignant tumor was assessed to be a benign tumor. Pleomorphic adenoma was one of the most common benign tumors in this study. Figure 2 shows cytological images of pleomorphic adenoma with its characteristic biphasic pattern, comprising epithelial/myoepithelial cells and fibromyxochondroid stroma.

In this study, of 103 cases of benign tumor, 100 cases were diagnosed using FNAC; of 11 malignant cases, 8 were diagnosed with FNAC. The overall accuracy of FNAC for parotid masses was estimated to be $95 \%$, which is in the same range as in previous studies, $12,22-24,30$. False-negative

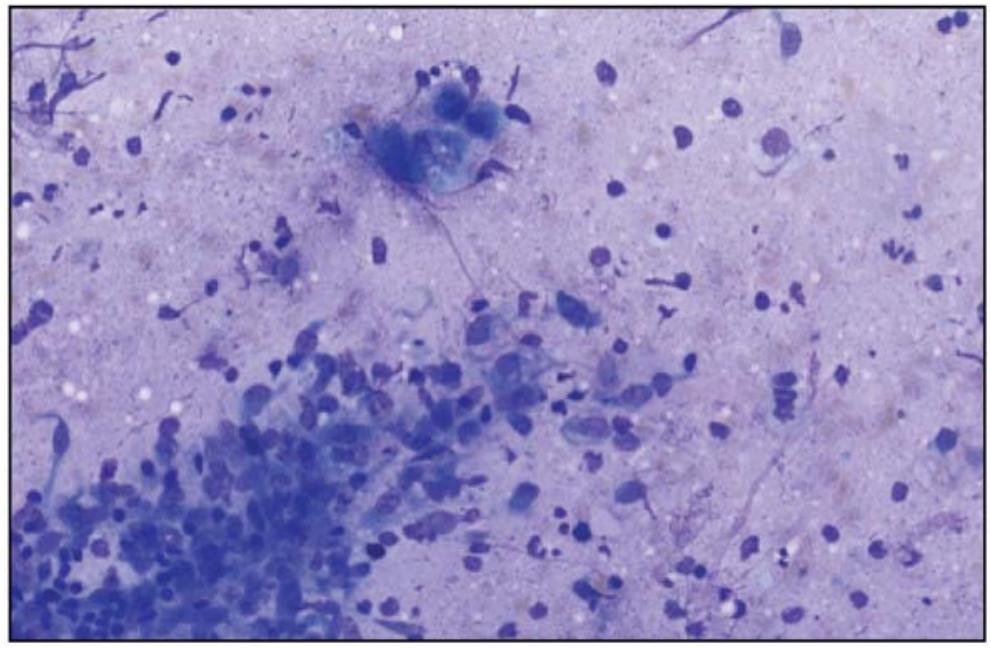

Figure 1- A low-grade mucoepidermoid carcinoma with thick mucinous material, intermediate cells, and only rare mitotic figures. Magnification: $100 x$

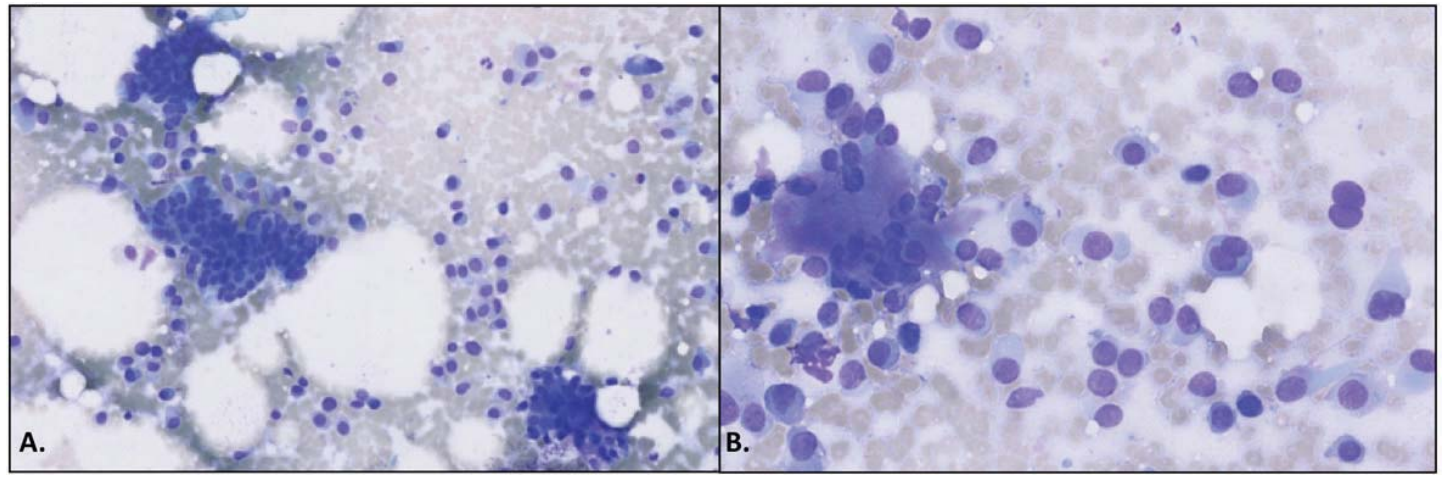

Figure 2- Patient with a pleomorphic adenoma with an epithelial cell component, a myoepithelial cell component, and a stromal (mesenchymal) component. Magnification: panel A, 100x; panel B, 200x 
Table 3- Sensitivity and specificity of fine-needle aspiration cytology (FNAC) for parotid gland tumors. Comparison with previous studies

\begin{tabular}{|c|c|c|c|}
\hline Authors & Number & Sensitivity (\%) & Specificity (\%) \\
\hline Orell²0 (1995) & 325 & 85.5 & 99.5 \\
\hline Al Khafaji, et al.2 (1998) & 154 & 82 & 86 \\
\hline Stewart, et al. ${ }^{26}$ (2000) & 341 & 92 & 100 \\
\hline Zbaren, et al..$^{30}$ (2001) & 228 & 64 & 95 \\
\hline Postema, et al..22 (2004) & 388 & 88 & 99 \\
\hline Seethala, et al. ${ }^{24}$ (2005) & 220 & 86 & 92 \\
\hline Aversa, et al. ${ }^{4}(2006)$ & 310 & 83 & 100 \\
\hline Lin, et al. ${ }^{18}(2007)$ & 279 & 63 & 97 \\
\hline Carrillo, et al. ${ }^{6}$ (2009) & 135 & 92 & 98 \\
\hline Jafari, et al. ${ }^{17}$ (2009) & 110 & 67 & 96 \\
\hline Schmidt, et al. ${ }^{23}$ (2011) & 6169 & 80 & 97 \\
\hline Fakhry, et al. ${ }^{12}$ (2012) & 202 & 80 & 89.5 \\
\hline $\begin{array}{l}\text { Gudmundsson, et al. (2016) } \\
\text { (this study) }\end{array}$ & 114 & 73 & 97 \\
\hline
\end{tabular}

diagnosis was found in mucoepidermoid carcinoma $(n=1 ; 1.4 \%)$, acinic cell carcinoma $(n=1 ; 1.4 \%)$, and epithelial-myoepithelial carcinoma $(n=1$; $1.4 \%)$, and there was false-positive diagnosis in cases of pleomorphic adenoma $(n=2 ; 2.7 \%)$ and in normal parotid tissue $(n=1 ; 1.4 \%)$. Diagnosis of low-grade mucoepidermoid carcinoma is difficult due to its extreme morphological heterogeneity; it may be misdiagnosed as Warthin's tumor or mucous retention cysts.

A review of the literature showed a FNAC sensitivity ranging from $54 \%$ to $92 \%$ and a specificity of $86-100 \%$ 2,4,6,12,17,18,20,22-24,26,30. These findings are summarized in Table 3. Parotid gland tumors account for approximately $3 \%$ of head and neck tumors and $80 \%$ of salivary gland tumors ${ }^{7,21}$. In this study, the incidence of pleomorphic adenoma and Warthin's tumor was estimated to be $65 \%$ and $17.5 \%$. FNAC was consistent with the final histological diagnosis in $98 \%$ of pleomorphic adenomas and in $100 \%$ of Warthin's tumors.

\section{CONCLUSION}

FNAC is a reliable method with high specificity for malignant parotid gland tumors, and provides the surgeon with valuable information in preoperative diagnostics. In this study, the sensitivity of FNAC in detection of malignant tumors was low due to the biopsy technique used, which depended on the location of the tumor. However, in cases where ultrasound guidance was used, $100 \%$ accuracy was achieved.

\section{ACKNOWLEDGEMENTS}

This study was supported by the Department of Oral and Maxillofacial Surgery, Linköping University Hospital, Sweden and the Department of Otorhinolaryngology, Eskilstuna Hospital, Sweden.

\section{Funding}

There was no funding.

\section{Conflicts of interests}

None of the authors have any financial or scientific conflicts of interests in relation to the data and conclusions presented in this manuscript.

\section{Ethical approval}

The study was approved by the Regional Committee for Ethics in Stockholm, Sweden (2015/1028-31/1). We also received permission by the authorities to review the patients' medical records.

\section{REFERENCES}

1- Ali NS, Akhtar S, J unaid M, Awan S, Aftab K. Diagnostic accuracy of fine needle aspiration cytology in parotid lesions. ISRN Surg. $2011 ; 2011: 721525$

2- Al-Khafaji BM, Nestok BR, Katz LR. Fine-needle aspiration of 154 parotid masses with histologic correlation. Cancer. 1998; 84: 153-9. 3- Atula T, Greénman R, Laippala P, Klemi PJ. Fine-needle aspiration biopsy in the diagnosis of parotid gland lesions: evaluation of 438 biopsies. Diagn Cytopathol. 1996; 15: 185-90.

4- Aversa S, Ondolo C, Bollito E, Fadda G, Conticello S. Preoperative cytology in the management of parotid neoplasms. Am J Otolaryngol. 2006; 27:96-100.

5- Batsakis JG, Sneige N, el-Naggar AK. Fine-needle aspiration of salivary glands: its utility and tissue effects. Ann Otol Rhinol Laryngol. 1992; 101(2 Pt 1): 185-8. 
6- Carrillo J F, Ramírez R, Flores L, Ramirez-Ortega MC, Arrecillas $M D$, Ibarra $M$, et al. Diagnostic accuracy of fine-needle aspiration biopsy in preoperative diagnosis of patients with parotid gland masses. J Surg Oncol. 2009; 100:133-8.

7- Cederblad L, Johansson S, Enblad G, Engström M, Blomquist E. Cancer of the parotid gland; long-term follow-up. A single centre experience on recurrence and survival. Acta Oncol. 2009; 48(4): 549-55.

8- Di Palma S, Simpson RH, Skálová A, Michal M. Metaplastic (infarcted) Warthin's tumour of the parotid gland: a possible consequence of fine needle aspiration biopsy. Histopathology. 1999; 35(5): 432-8.

9- Dulguerov P, Marchal F, Lehmann W. Postparotidectomy facial nerve paralysis: possible etiologic factors and results with routine facial nerve monitoring. Laryngoscope. 1999; 109(5): 754-62.

10- El Fol HA, Beheiri MJ, Zaqri WA. Comparison of the effect of total conservative parotidectomy versus superficial parotidectomy in management of benign parotid gland tumor: a systematic review. J Craniomaxillofac Surg. 2015; pii:S1010-5182(15)00012-8. Epub ahead of print.

11- Engzell U, Esposti L, Rubio G, Sigurdson A, Zajicek J. Investigation on tumour spread in connection with aspiration biopsy. Acta Radiol Ther Phys Biol. 1971; 10: 385-98.

12- Fakhry N, Antonini F, Michel J, Penicaud M, Mancini J, Lagier A, et al. Fine-needle aspiration cytology in the management of parotid masses: evaluation of 249 patients. Eur Ann Otorhinolaryngol Head Neck Dis. 2012; 3: 131-5.

13- Haldar S, Mandalia U, Skelton E, Chow V, Turner SS, Ramesar $K$, et al. Diagnostic investigation of parotid neoplasms: a 16year experience of freehand fine needle aspiration cytology and ultrasound-guided core needle biopsy. Int J Oral Maxillofac Surg. 2015; 44(2): 151-7.

14- Howlett DC, Skelton E, Moody AB. Establishing an accurate diagnosis of a parotid lump: evaluation of the current biopsy methods - fine needle aspiration cytology, ultrasound-guided core biopsy, and intraoperative frozen section. Br J Oral Maxillofac Surg. 2015; 53(7):580-3.

15- Huang YC, Wu CT, Lin G, Chuang WY, Yeow KM, Wan YL. Comparison of ultrasonographically guided fine-needle aspiration and core needle biopsy in the diagnosis of parotid masses. J Clin Ultrasound. 2012; 4: 189-94.

16- Inohara H, Akahani S, Yamamoto $\mathrm{Y}$, Hattori K, Tomiyama $\mathrm{Y}$, Tomita $Y$, et al. The role of fine-needle aspiration cytology and magnetic resonance imaging in the management of parotid mass lesions. Acta Otolaryngol. 2008; 128(10): 1152-8.
17- Jafari A, Royer B, Lefevre M, Corlieu P, Périé S, St Guily J L. Value of the cytological diagnosis in the treatment of parotid tumors. Otolaryngol Head Neck Surg. 2009; 3:381-5.

18- Lin AC, Bhattacharyya N. The utility of fine-needle aspiration in parotid malignancy. Otolaryngol Head Neck Surg. 2007; 136: 7938.

19- Miliauskas JR, Orell SR. Fine-needle aspiration cytological findings in five cases of epithelial-myoepithelial carcinoma of salivary glands. Diagn Cytopathol. 2003;28(3):163-7.

20- Orell SR. Diagnostic difficulties in the interpretation of fineneedle aspirates of salivary gland lesions: the problem revisited. Cytopathology. 1995; 6:285-300.

21- Pinkston JA, Cole P. Incidence rates of salivary gland tumors: results from a population-based study. Otolaryngol Head Neck Surg. 1999; 120(6): 834-40.

22- Postema RJ, van Velthuysen ML, van den Brekel MW Balm AJ, Peterse JL. Accuracy of fine-needle aspiration cytology of salivary gland lesions in The Netherlands Cancer Institute. Head Neck. 2004; 26: 418-24.

23- Schmidt RL, Hall BJ, Wilson AR, Layfield LJ. A systematic review and meta-analysis of the diagnostic accuracy of fine-needle aspiration cytology for parotid gland lesions. Am J Clin Pathol. 2011; 1: 45-59.

24- Seethala RR, LiVolsi VA, Baloch ZW. Relative accuracy of fineneedle aspiration and frozen section in the diagnosis of lesions of the parotid gland. Head Neck. 2005; 27:217-23.

25- Shinohara S, Yamamoto E, Tanabe M, Maetani T, Kim T. Implantation metastasis of head and neck cancer after fine needle aspiration biopsy. Auris Nasus Larynx. 2001;28(4):377-80.

26- Stewart CJ, MacKenzie K, McGarry GW, Mowat A. Fine-needle aspiration cytology of salivary gland: a review of 341 cases. Diagn Cytopathol. 2000;22(3): 139-46.

27- Terrell JE, Kileny PR, Yian C, Esclamado RM, Bradford CR, Pillsbury MS, et al. Clinical outcome of continuous facial nerve monitoring during primary parotidectomy. Arch Otolaryngol Head Neck Surg. 1997; 123(10): 1081-7.

28- Urquhart A, Hutchins LG, Berg RL. Preoperative computed tomography scans for parotid tumor evaluation. Laryngoscope. 2001; 111(11 Pt 1): 1984-8.

29- Wittekindt C, Streubel K, Arnold G, Stennert E, GuntinasLichius $O$. Recurrent pleomorphic adenoma of the parotid gland: analysis of 108 consecutive patients. Head Neck. 2007; 9:822-8. 30- Zbären $\mathrm{P}$, Schär C, Hotz MA, Loosli H. Value of fine-needle aspiration cytology of parotid gland masses. Laryngoscope. 2001; 111: 1989-92. 